\title{
PEMBENTUKAN PORTOFOLIO OPTIMAL PADA BEBERAPA SAHAM YANG MASUK PADA INDEKS PEFINDO25 YANG TERCATAT DI BURSA EFEK INDONESIA
}

\author{
Chalimatuz Sa'diyah \\ Department of Management FEB UMM \\ Email: Chalimatuz120@gmail.com
}

\begin{abstract}
This study aims to determine the stock that form the optimal portofolio and the proportion of funds invested and determine the rate of return and level of risk of the optimal portofolio of stocks that, is formed in the PEFINDO25 index listed on Indonesian Stock Exchange, in the study period at August 2011 to July 2013. The method of analysis used in this study is a single index model method and sampling techniques using purposive sampling. Based on the results of data analysis stocks that form the optimal portofolio in PEFINDO25 index in the period at August 2011 - July 2013, obtained three stocks included in the optimal portofolio members. The share are accompanied by the proportion of investment funds is BISI (BISI International Tbk) 48,4379\%, GZCO (Gozco Plantations Tbk) 31,3017\%, HRUM (Harum Energy Tbk) 20,2604\%,. The stocks are result yield rate of return on a portofolio that will get investors at 0,151\% and the portofolio risk level of 0,003\%.
\end{abstract}

Keywords: PEFINDO25, Optimal Portofolio, Single Index Model, Return and Risk

\section{PENDAHULUAN}

Pasar modal Indonesia hingga saat ini dinilai masih cukup kuat menahan sentimen negatif eksternal sehingga dana investor asing (capital inflow) masih deras mengalir ke dalam negeri. "Investasi di pasar modal Indonesia cukup mudah dan paling kuat menahan sentimen," ujar Direktur Utama Kresna Securities, Michael Steven saat konferensi pers "Online Trading Academy (OTA)" di Jakarta.

Menurut dia, kondisi itu merupakan kesempatan bagi masyarakat Indonesia, jika tidak negara tetangga yang akan mengambil kesempatan itu (www.investor.co.id, diunduh tanggal 4 Februari 2014).

Kinerja bursa saham Indonesia dari tahun ke tahun terus meningkat. Ekspektasi terhadap pertumbuhan ekonomi Indonesia yang tinggi tahun ini memicu derasnya aliran dana investor asing masuk ke bursa saham Indonesia.

Berdasarkan data Bloomberg, bursa saham Indonesia tercatat naik $10,08 \%$. Pertumbuhan kapitalisasi bursa saham Indonesia sepanjang Januari 2013 sebesar 7,6\% senilai Rp 4.386 triliun (www.iyaa.com, diunduh tanggal 3 Oktober 2013). Dua bulan berjalan di semester II tahun ini, pergerakan Indeks Harga Saham 
Gabungan (IHSG) terlihat begitu bergejolak.

IHSG mencetak kinerja cemerlang per Juli 2012 sebesar $4,72 \%$, namun ramainya ketidakpastian global yang disertai lesunya data-data ekonomi negaranegara besar, seperti Uni Eropa dan China, membuat kinerja IHSG merosot $-1,98 \%$ sepanjang Agustus 2012. Meskipun demikian, kinerja IHSG pada Agustus 2012 masih sukses mencetak angka positif, yakni $6,24 \%$.

Pengukuran untuk mendapatkan indeks saham yang berkinerja paling baik mencakup sisi pengembalian dan risiko dapat disesuaikan dalam kondisi tertentu. Berikut ini terdapat data Pengembalian dan Risiko Tahunan yang dapat mewakili beberapa indeks yang tercatat di BEI dengan periode sepanjang 3 tahun terakhir (Juli 2009 - Juli 2012). Data Pengembalian dan Risiko Tahunan dapat dilihat pada Tabel 1.1.

Dari Tabel 1.1, terlihat kinerja indeks PEFINDO25 menjadi yang teratas berdasarkan pengembalian per Juli 2012 maupun 3 tahun terakhir (Juli 2009 - Juli 2012), masing-masing $19,07 \%$ dan $153,21 \%$ jauh di atas kinerja IHSG dan LQ-45. Bahkan, bila dibandingkan dengan kinerja indeks Reksa Dana Saham (IRDSH) yang mencerminkan rata-rata pergerakan Reksa Dana Saham secara keseluruhan, kinerja PEFINDO25 juga lebih unggul lebih dari dua kali lipat (www.infovesta.com, diunduh tanggal 9 Oktober 2013).

Kondisi

tersebut memungkinkan investor dapat meraih pengembalian tinggi apabila investor berinvestasi pada saham-saham yang tergabung dalam indeks PEFINDO25.

Berdasarkan penjelasan yang sudah diuraikan di atas, maka penulis tertarik untuk melakukan penelitian dengan judul "Pembentukan Portofolio Optimal Pada Beberapa Saham Yang Masuk Pada Indeks PEFINDO25 yang Tercatat di Bursa Efek Indonesia".

Berdasarkan latar belakang yang telah diuraikan di atas, maka dirumuskan masalah tentang "Sahamsaham apa saja yang terbentuk dalam portofolio optimal pada saham indeks

Tabel 1.1 Pengembalian dan Risiko Tahunan beberapa indeks yang tercatat di BEI

\begin{tabular}{lllll}
\hline \multirow{2}{*}{ Indeks Saham } & \multicolumn{2}{c}{ Per Juli 2012 } & \multicolumn{2}{c}{ Juli 2009 - Juli 2012 } \\
\cline { 2 - 5 } & Pengembalian & $\begin{array}{l}\text { Risiko } \\
\text { Tahunan }\end{array}$ & Pengembalian & $\begin{array}{l}\text { Risiko } \\
\text { Tahunan }\end{array}$ \\
\hline PEFINDO25 & $19.07 \%$ & $0.60 \%$ & $153.21 \%$ & $2.18 \%$ \\
Sri Kehati & $9.52 \%$ & $8.60 \%$ & $8.71 \%$ & $3.11 \%$ \\
IHSG & $8.38 \%$ & $5.83 \%$ & $8.30 \%$ & $0.66 \%$ \\
Bisnis-27 & $8.19 \%$ & $19.17 \%$ & $69.58 \%$ & $23.90 \%$ \\
JI & $6.83 \%$ & $8.80 \%$ & $8.94 \%$ & $3.58 \%$ \\
IRDSH & $.61 \%$ & $6.81 \%$ & $4.24 \%$ & $1.67 \%$ \\
LQ45 & $5.83 \%$ & $8.56 \%$ & $6.85 \%$ & $3.42 \%$ \\
\hline
\end{tabular}


PEFINDO25?, Bagaimana proporsi dana saham-saham anggota indeks PEFINDO25 yang terbentuk dalam portofolio optimal? dan Berapa tingkat risiko dan tingkat pengembalian (return) dari portofolio optimal saham yang terbentuk?

Penentuan batasan penelitian dalam penelitian ini adalah periode penelitan yaitu Agustus 2011 sampai Juli 2013 dengan menggunakan data harga saham mingguan indeks PEFINDO25 dan harga saham mingguan perusahaan yang termasuk dalam indeks PEFINDO25.

Tujuan dari penelitian ini adalah untuk mengetahui sahamsaham anggota indeks PEFINDO25 yang terbentuk dalam portofolio optimal, untuk mengetahui proporsi dana saham-saham anggota indeks PEFINDO25 yang terbentuk dalam portofolio optimal dan untuk mengetahui besarnya tingkat risiko dan tingkat pengembalian (return) dari portofolio optimal saham yang terbentuk.

\section{TINJAUAN PUSTAKA}

Galang Nasution (2013) dengan judul Analisis Pembentukan Portofolio Optimal Pada Indeks SriKehati Yang Tercatat Di Bursa Efek Indonesia. Hasil penelitian tersebut terdapat 2 saham yang termasuk dalam portofolio optimal beserta proporsi dananya adalah AALI (Astra Argo Lestari Tbk) 64,23\% dan TLKM (Telekomunikasi Indonesia Tbk) $35,77 \%$, serta menghasilkan tingkat pengembalian portofolio yang akan investor dapatkan sebesar $1,023 \%$ dan tingkat risiko portofolio sebesar $0,003 \%$.

$$
\text { Jogianto, }
$$

mendefinisikan investasi sebagai penundaan konsumsi sekarang untuk dimasukkan ke aktiva produktif selama periode waktu yang tertentu. Dasar keputusan investasi terdiri dari tingkat return yang diharapkan, tingkat risiko, serta hubungan antara return dan risiko.

Tujuan investor dalam berinvestasi adalah memaksimalkan pengembalian, tanpa melupakan faktor risiko investasi yang harus dihadapinya. Portofolio merupakan kombinasi atau gabungan atau sekumpulan assets, baik berupa real assets atau financial assets yang dimiliki oleh investor (Halim, 2005:63).

Portofolio-portofolio efisien berada di efficient set. Portofolioportofolio efisien merupakan portofolio-portofolio yang baik, tetapi bukan yang terbaik. Portofolio optimal merupakan portofolio yang dipilih seorang investor dari sekian banyak pilihan yang ada pada kumpulan portofolio efisien (Tandelilin, 2001:74).

Single Index Model adalah sebuah teknik untuk mengukur pengembalian dan risiko sebuah saham atau portofolio. Model tersebut mengasumsikan bahwa pergerakan pengembalian saham hanya berhubungan dengan pergerakan pasar. Model indeks tunggal dapat juga dinyatakan dalam bentuk pengembalian ekspektasian (expected return).

$\begin{array}{ccr}\text { Tidak } & \text { seperti } & \text { halnya } \\ \text { pengembalian } & \text { portofolio } & \text { yang }\end{array}$ merupakan rata-rata tertimbang dari seluruh pengembalian sekuritas tunggal, risiko portofolio (portofolio risk) tidak merupakan rata-rata tertimbang dari seluruh risiko sekuritas tunggal. Risiko portofolio 
mungkin dapat lebih kecil dari risiko rata-rata tertimbang masing-masing. Risiko portofolio menunjukkan bahwa secara umum risiko mungkin dapat dikurangi dengan menggabungkan beberapa sekuritas tunggal ke dalam bentuk portofolio. Persyaratan utama untuk dapat mengurangi risiko di dalam portofolio ialah pengembalian masing-masing sekuritas tidak berkorelasi secara positif dan sempurna.

Pengembalian dan risiko mempunyai hubungan yang positif, semakin besar risiko yang ditanggung maka semakin besar pengembalian yang harus dikompensasikan. Risiko dari investasi juga perlu dipertimbangkan, oleh karenanya pengembalian dan risiko merupakan dua hal yang tidak terpisah dan pertimbangan suatu investasi merupakan trade-off dari kedua faktor ini.

\section{METODE PENELITIAN}

Jenis penelitian yang digunakan adalah penelitian deskriptif dengan pendekatan kuantitatif terhadap fenomena atau populasi tertentu.

Definisi operasional variabel dalam penelitian ini adalah Harga saham yang digunakan dalam penelitian ini adalah harga saham mingguan dalam periode Agustus 2011 sampai dengan Juli 2013. Tingkat suku bunga SBI digunakan untuk mengukur tingkat pengembalian bebas risiko (risk free rate of return). Tingkat suku bunga SBI (Sertifikat Bank Indonesia) diperoleh dari laporan Bank Indonesia selama periode Agustus 2011 sampai dengan periode Juli
2013. Return Realisasi atau (Ri) merupakan pengembalian yang telah terjadi. Pengembalian realisasi dihitung berdasarkan data historis.

$$
R_{i}=\frac{\left(P_{t}-\left(P_{t-1}\right)\right)}{P_{t-1}}
$$

Keterangan:

$R_{\tilde{i}}$ : Tingkat keuntungan dari suatu saham.

$P_{t} \quad$ : Harga saham periode ke-t.

$P_{t-1}$ : Harga saham sebelum periode ke-t.

Return Ekspektasi merupakan pengembalian yang diharapkan akan diperoleh oleh investor di masa mendatang.

$$
\mathrm{E}(\mathrm{Ri})=\frac{\sum_{\mathrm{i}=1}^{\mathrm{n}} \mathrm{Rij}}{\mathrm{n}}
$$

Keterangan:

E(Ri) : Tingkat keuntungan yang diharapkan dari saham i.

Rij : Pengembalian untuk kemungkinan ke-j.

n : Jumlah observasi.

Risiko Investasi adalah besarnya penyimpangan antara tingkat pengembalian yang diharapkan dengan tingkat pengembalian yang dicapai secara nyata.

$$
\mathrm{SD}=\sqrt{\frac{\sum_{\mathrm{i}=1}^{\mathrm{n}}(\mathrm{Ri}-\mathrm{ERi})^{2}}{\mathrm{n}-1}}
$$

Keterangan:

SD : Standar deviasi (SD)

$\mathrm{Ri}$ : Tingkat keuntungan dari saham i. 
ERi : Tingkat keuntungan yang diharapkan.

n : Jumlah dari observasi.

Variance digunakan untuk mengukur risiko expected return saham variance dapat dihitung dengan mengkuadratkan standar deviasi.

$$
\begin{gathered}
\operatorname{Var}=\left(\sigma^{2} \mathrm{i}\right) \\
\text { Atau } \\
\left(\sqrt{\frac{\sum_{\mathrm{i}=1}^{\mathrm{n}}(\mathrm{Ri}-\mathrm{ERi})^{2}}{\mathrm{n}-1}}\right)^{2}
\end{gathered}
$$

Risiko Sistematis merupakan risiko yang tidak dapat dihilangkan dengan jalan diversifikasi, risiko ini dapat tetap ada pada saham.

$$
\beta \mathrm{i}=\frac{\sigma \mathrm{im}}{\sigma \mathrm{m}^{2}}
$$

Pengembalian pasar (Rm) yaitu tingkat pengembalian indeks pasar yang diukur dengan menggnakan indeks PEFINDO25.

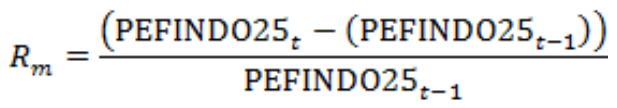

Keterangan:

Rm : Pengembalian pasar periode ke-t.

PEFINDO25 $_{\mathrm{t}}$ : Indeks PEFINDO25 periode ke-t.

PEFIND025 ${ }_{\mathrm{t}-1}$ :Indeks PEFINDO25 periode $\mathrm{t}-1$

Return ekspektasi pasar atau $\mathrm{E}(\mathrm{Rm})$ adalah pengembalian pasar yang diharapkan di masa mendatang.

$$
\mathrm{E}(\mathrm{Rm})=\frac{\sum \mathrm{Rm}}{\mathrm{n}}
$$

Keterangan:

$\mathrm{E}(\mathrm{Rm})$ :Pengembalian ekspektasi pasar.

Rm :Tingkat keuntungan pasar.

n :Jumlah observasi.

Menghitung koefisien $\alpha$ (Alpha) dan $\beta$ (Beta) saham. Alpha diartikan sebagai komponen dari pengembalian sekuritas yang independen terhadap kinerja pasar dan beta diartikan sebagai pengukur risiko sistematik dari suatu sekuritas atau portofolio relatif terhadap pasar. Secara sistematis dapat dirumuskan dengan rumus sebagai berikut:

$$
\begin{gathered}
\mathrm{b}=\frac{\mathrm{n} \sum \mathrm{XY}-\sum \mathrm{x} \sum \mathrm{Y}}{\mathrm{n} \sum \mathrm{x}^{2}-\left(\sum \mathrm{X}\right)^{2}} \\
\text { dengan } \\
\mathrm{Y}=\mathrm{a}+\mathrm{bX}
\end{gathered}
$$

Keterangan:

$\mathrm{X}$ : Pengembalian Pasar (Rm)

$\mathrm{Y}$ : Pengembalian Saham (Ri)

A $: \alpha$ (Alpha)

b $\quad: \beta$ (Beta) Koefisien Risiko

Varian ini adalah varian dari kesalahan residu sekuritas ke-i yang juga merupakan risiko unik atau risiko tidak sitematik. Secara matematis dapat dirumuskan:

$$
\vartheta_{\mathrm{ei}}^{2}=\frac{\sum\left[\mathrm{R}_{\mathrm{it}}-\left(\alpha_{\mathrm{i}}-\beta_{\mathrm{i}} \cdot \mathrm{R}_{\mathrm{mt}}\right)\right]^{2}}{\mathrm{n}-1}
$$

Keterangan:

$\vartheta_{\text {ei }}{ }^{2}$ : Varian dari kesalahan residu sekuritas ke-i. 
$\mathrm{R}_{\mathrm{it}}$ : Pengembalian sekuritas $\mathrm{i}$ periode $\mathrm{t}$.

$\alpha_{\mathrm{i}} \quad$ : Alpha sekuritas ke-i.

$\beta_{\mathrm{i}} \quad$ : Beta sekuritas ke $-\mathrm{i}$.

$\mathrm{R}_{\mathrm{mt}} \quad$ : Return market periode ke-t.

Excess Return to Beta (ERB) merupakan kelebihan pengembalian berupa selisih antara pengembalian yang diperkirakan atas sebuah asset dengan tingkat pengembalian bebas risiko.

$$
E R B i=\frac{E(R i)-R f}{\beta i}
$$

Keterangan:

ERBi : Excess return to beta saham i.

E(Ri) : Expected return saham i.

Rf : Risk free rate of return.

Bi : Beta saham i.

Cut off rate $\mathrm{Ci}$ merupakan angka pembatas yang menentukan nilai ERB berapa yang dikatakan tinggi.

$$
\begin{aligned}
& \mathrm{Ci}=\frac{\sigma \mathrm{m}^{2} \sum_{\mathrm{j}}^{\mathrm{i}} \mathrm{Ai}}{1+\sigma^{2} \mathrm{~m} \sum_{\mathrm{j}}^{\mathrm{i}} \mathrm{Bi}} \\
& \mathrm{Ai}=\frac{\left[\mathrm{E}\left(\mathrm{R}_{\mathrm{i}}\right)-\mathrm{R}_{\mathrm{f}}\right] \beta \mathrm{i}}{\sigma_{\mathrm{ei}}} \\
& \beta \mathrm{i}=\frac{{\beta_{\mathrm{i}}}^{2}}{\sigma_{\mathrm{ei}}{ }^{2}}
\end{aligned}
$$

Berdasarkan hasil subtitusi $\mathrm{Aj}$ dan $\mathrm{Bj}$ ke nilai $\mathrm{Ci}$ didapatkan persamaan sebagai berikut:

$$
\mathrm{Ci}=\frac{\sigma \mathrm{m}^{2} \sum_{\mathrm{j}=1}^{\mathrm{i}} \frac{(\mathrm{E}(\mathrm{Ri})-\mathrm{Rf}) \beta \mathrm{i}}{\sigma e \mathrm{i}^{2}}}{1+\sigma \mathrm{m}^{2} \sum_{\mathrm{j}=1}^{\mathrm{i}} \frac{\beta \mathrm{i}^{2}}{\sigma e \mathrm{i}^{2}}}
$$

Keterangan:

Ci : Cut-off-rate

Ri : Rata-rata return saham ke-i.

Rf : Pengembalian untuk aset bebas risiko.

$\sigma \mathrm{m}^{2}$ : Varians dari RM (indeks pasar).

$\sigma \mathrm{ei}^{2}$ : Varians untuk residu masing-masing saham.

$\beta \mathrm{i}^{2}$ : Kuadrat dari risiko sistematis masing-masing saham.

Proporsi merupakan jumlah besaran dana dari masing-masing sekuritas dalam portofolio optimal.

$$
\begin{aligned}
& \mathrm{Wi}=\frac{\mathrm{Zi}}{\sum_{\mathrm{j}=1}^{\mathrm{k}} \mathrm{Zi}} \\
& \text { dengan } \\
& \mathrm{Zi}=\frac{\beta \mathrm{i}(\mathrm{ERBi}-\mathrm{C} *)}{\sigma \mathrm{ei}^{2}}
\end{aligned}
$$

Keterangan:

Wi : Proporsi sekuritas ke-i.

K : Jumlah sekuritas pada portofolio optimal.

Bi : Beta sekuritas ke-i.

$\sigma \mathrm{ei}^{2}$ : Varians kesalahan residu sekuritas ke-i.

ERBi : Excess return to beta sekuritas ke-i.

$\mathrm{C} * \quad$ : Nilai Cut-off rate merupakan nilai Ci terbesar. 
Return dan risiko berdasarkan model indeks tunggal. Return portofolio

$$
\mathrm{E}\left(\mathrm{R}_{\mathrm{p}}\right)=\alpha_{\mathrm{p}}+\beta_{\mathrm{p}} \cdot \mathrm{E}\left(\mathrm{R}_{\mathrm{m}}\right)
$$

Keterangan:

$E\left(R_{p}\right)$ :Tingkat keuntungan yang diharapkan pada portofolio.

$\alpha_{\mathrm{p}} \quad$ : Rata-rata tertimbang dari

alpha tiap-tiap sekuritas.

$\beta_{\mathrm{p}} \quad$ : Rata-rata tertimbang dari

beta tiap-tiap sekuritas.

$\mathrm{E}\left(\mathrm{R}_{\mathrm{m}}\right)$ : Expected return market.

Risiko portofolio

$$
\sigma_{\mathrm{p}^{2}}=\beta_{\mathrm{p}}{ }^{2} \cdot \sigma_{\mathrm{m}}{ }^{2}+\left(\sum_{\mathrm{i}=1}^{2} \mathrm{~W}_{\mathrm{i}} \cdot \sigma_{\mathrm{ei}}\right)^{2}
$$

Keterangan:

$\sigma_{\mathrm{p}^{2}}$ : Varian portofolio.

$\beta_{\mathrm{p}}$ : Beta portofolio.

$\sigma_{\mathrm{m}}^{2}$ : Varian market.

$\mathrm{W}_{\mathrm{i}}$ : Proporsi sekuritas ke-i.

$\sigma_{\text {ei }}$ : Varians dari kesalahan residu

ke-i.

Data dalam penelitian ini yaitu menggunakan data kuantitatif. Data kuantitatif dalam penelitian ini berupa data harga saham penutupan perusahaan yang termasuk dalam indeks PEFINDO25 periode Agustus 2011 sampai Juli 2013 yang disajikan dalam harga saham mingguan. Data harga saham indeks PEFINDO25 periode Agustus 2011 sampai Juli 2013 yang disajikan dalam harga saham mingguan. Data suku bunga Sertifikat Bank Indonesia (SBI) periode Agustus 2011 sampai Juli 2013.

Sumber data yang digunakan dalam penelitian ini berasal dari harga saham perusahaan yang termasuk dalam indeks PEFINDO25, harga saham indeks PEFINDO25 dan suku bunga SBI selama periode Agustus 2011 sampai Juli 2013 yang tercatat di Bursa Efek Indonesia dan Bank Indonesia.

Teknik pengumpulan data dalam penelitian ini dilakukan dengan menggunakan teknik dokumentasi. Teknik tersebut dilakukan dengan cara mengumpulkan data dari literatur, penelitian terdahulu, dan laporan-laporan yang dipublikasikan oleh Bank Indonesia dan Bursa Efek Indonesia.

Populasi dalam penelitian ini adalah saham-saham perusahaan yang tergabung dalam indeks PEFINDO25 yang terdaftar dan aktif diperdagangkan di Bursa Efek Indonesia serta secara berturut-turut tergabung dalam saham indeks PEFINDO25 pada periode Agustus 2011 sampai dengan Juli 2013. Pengambilan sampel dilakukan dengan teknik purposive sampling yaitu seleksi sampel yang didasarkan pada kriteria tertentu.

Teknik yang digunakan dalam menganalisis data untuk membentuk portofolio optimal yaitu dengan menggunakan program Microsoft Excel 2013. Adapun metode yang digunakan untuk menentukan portofolio yang optimal adalah metode indeks tunggal. Langkahlangkah yang akan dilakukan untuk pemilihan dan pembentukan portofolio optimal yaitu, Menghitung ERB (Excess return to beta). Menghitung $\mathrm{Ci}$ (Cut off rate) masing- 
masing saham, yang kemudian digunakan untuk menentukan nilai Cut off point $\mathrm{C}^{*}$. Menentukan saham pembentuk portofolio optimal, dengan syarat ERB (Excess return to beta) harus sama atau lebih dari nilai $\mathrm{C}^{*}$ (Cut of point). Menghitung proporsi dana masing-masing saham portofolio yang terbentuk pada saham portofolio optimal. Menghitung pengembalian dan risiko portofolio pada saham portofolio optimal.

\section{HASIL PENELITIAN DAN PEMBAHASAN}

Menghitung ERB (Excess

Return to Beta), dalam menghitung Pengembalian Individual Saham dan Pengembalian yang Diharapkan Pada Saham didapatkan sebuah hasil perhitungan pengembalian yang diharapkan menunjukkan bahwa diketahui rata-rata tingkat pengembalian yang diharapkan sebesar $\quad 0,3522 \%$ dimana pengembalian yang diharapkan terbesar dimiliki oleh SSIA yaitu sebesar 1,4777\%. Sedangkan pengembalian yang diharapkan terendah dimiliki oleh TBLA yaitu sebesar $-0,0857 \%$.

Menghitung Pengembalian Pasar(Rm) yaitu tingkat pengembalian indeks pasar yang diukur dengan menggunakan indeks PEFINDO25. Pengembalian pasar yang diharapkan merupakan tingkat pengembalian pasar yang diharapkan di masa mendatang yaitu sebesar 0,134\%. Menghitung Risiko Saham dengan Standar Deviasi, tingkat risiko perlu diperhatikan dalam keputusan berinvestasi. Risiko menggambarkan hubungan tingkat penyimpangan atau deviasi. Berdasarkan hasil perhitungan yang memiliki risiko tertinggi yaitu BWPT sebesar 0,0996271 dan risiko terendah dimiliki oleh SGRO sebesar 0,0045450 .

Menghitung Koefisien Alpha dan Beta Saham, Alpha diartikan sebagai komponen dari pengembalian sekuritas yang independen terhadap kinerja pasar. Beta merupakan pengukur risiko sistematik dari suatu portofolio relatif terhadap risiko pasar.

Dari hasil perhitungan tersebut dapat dilihat saham yang memiliki alpha tertinggi yaitu RALS sebesar 0,006621 dan beta tertinggi yaitu SSIA sebesar 1,994894. Sedangkan yang memiliki alpha terendah yaitu TBLA sebesar 0,00061 dan beta terendah yaitu GZCO sebesar -0,24391.

Menghitung Varian dari Kesalahan Residu Saham, Penyimpangan dari sekuritas merupakan risiko yang berhubungan dengan risiko masing-masing saham. Risiko menggambarkan hubungan tingkat penyimpangan atau deviasi.

Menghitung ERB (Excess Return to Beta), ERB merupakan selisih dari pengembalian yang diharapkan dengan pengembalian aktiva bebas risiko dan kelebihan pengembalian relatif terhadap satu unit risiko yang tidak dapat didiversifikasi dapat diukur dengan beta. Hasil perhitungan menunjukkan nilai ERBi tertinggi dimiliki oleh INTA yaitu sebesar 0,974789896 sedangkan nilai ERBi terendah dimiliki oleh SGRO yaitu sebesar 0,250046908.

Menghitung $\mathrm{Ci}$ (Cut of rate) Masing-masing Saham, perhitungan $\mathrm{Ci}$ bertujuan untuk mengetahui titik pembatas untuk menentukan 
perusahaan-perusahaan mana saja yang masuk dalam kandidat portofolio optimal diperoleh dari perusahaan-perusahaan yang memiliki nilai ERB lebih besar dari nilai Ci. Hasil perhitungan menunjukkan nilai Cut-off point $\left(\mathrm{C}^{*}\right)$ yaitu sebesar 0,01416 dimiliki oleh GZCO.

Menghitung Proporsi Dana Masing-Masing Saham bertujuan agar investor mengetahui berapa besar dananya yang sebaiknya diinvestasikan ketika ingin melakukan investasi pada sahamsaham yang masuk pada portofolio optimal. Hasil perhitungan proporsi dana yaitu INTA sebesar 31,645\%, BISI sebesar 31,107\%, HRUM sebesar 13,011\%, TBLA sebesar 4,134\% dan GZCO sebesar 20,102\%.

Pengukuran kinerja portofolio dilakukan dengan memperhatikan tingkat pengembalian dan risiko portofolio. Hasil perhitungan diperoleh pengembalian portofolio tertinggi dimiliki oleh BISI yaitu sebesar 0,00045 dan pengembalian terendah dimiliki oleh INTA yaitu sebesar -0,00011. Hasil tersebut menunjukkan bahwa suatu portofolio optimal tidak selamanya optimal, karena dalam perhitungan pengembalian dari saham-saham yang masuk dalam portofolio optimal terdapat pengembalian portofolio dengan hasil negatif.

Berdasarkan hasil perhitungan ulang diperoleh proporsi dana portofolio yang optimal yaitu BISI sebesar 48,4379\%, GZCO sebesar $31,3017 \%$, HRUM sebesar $20,2604 \%$. Pengembalian portofolio masing-masing saham diperoleh sebagai berikut BISI dengan pengembalian sebesar 0,00070,
HRUM dengan pengembalian sebesar 0,00064 dan GZCO dengan pengembalian sebesar 0,00016 .

Sedangkan risiko yang dimiliki oleh masing-masing saham yaitu BISI dengan risiko sebesar 0,000008, HRUM dengan risiko sebesar 0,000003 dan GZCO dengan risiko sebesar 0,000014. Hal tersebut dapat disimpulkan bahwa tingkat pengembalian yang diperoleh dalam portofolio optimal pada periode penelitian memiliki pengembalian sebesar $0,00151(0,151 \%)$ dan risiko sebesar $0.00003(0,003 \%)$.

\section{SIMPULAN}

Berdasarkan analisis data dan pembahasan yang dilakukan diperoleh beberapa kesimpulan yaitu, saham-saham yang terbentuk dalam portofolio optimal pada indeks PEFINDO25 yaitu pada periode Agustus 2011 - Januari 2013 didapatkan 3 saham yang masuk sebagai anggota portofolio optimal. Saham-saham tersebut adalah BISI, HRUM, GZCO. Saham-saham yang terbentuk dalam portofolio optimal disertai proporsi dananya adalah BISI sebesar 48,4379\%, GZCO sebesar $31,3017 \%$, dan HRUM sebesar $20,2604 \%$. Portofolio yang terbentuk dari saham menghasilkan tingkat pengembalian portofolio yang akan investor dapatkan sebesar 0,151\% dan tingkat risiko portofolio sebesar $0,003 \%$.

Saran

\section{DAFTAR PUSTAKA}

Almunawir, Fitra, 2012, Pembentukan Portofolio Optimal Pada Saham Indeks LQ-45 Yang Tercatat Di 
Bursa Efek Indonesia, Skripsi UMM. Malang.

Damadji, T. dan Fakhruddin H. M, 2012, Pasar Modal Indonesia, Edisi ketiga, Salemba empat, Jakarta.

Halim, Abdul, 2005, Analisis Investasi, Salemba Empat, Jakarta.

Jogianto, 2010, Teori Portofolio dan Analisis Investasi, Edisi Ketiga, BPFE Yogyakarta, Yogyakarata.

Nasution, Galang, 2013, Analisis Pembentukan Portofolio Optimal Pada Indeks SriKehati Yang Tercatat Di Bursa Efek Indonesia, Skripsi UMM, Malang.

Sanusi, Anwar, 2011, Metodologi Penelitian Bisnis, Jilid 1, Salemba Empat, Jakarta.

Soeranto dan Arsyad Lincolin, 2003, Metodologi Penelitian, Edisi Revisi, UPP AMP YKPN, Yogyakarta.
Tandelilin, Eduardus, 2001, Analisis Investasi dan Manajemen Portofolio, Edisi 1, BPFE Yogyakarta, Yogyakarta.

Zubir, Zalmi, 2011, Manajemen Portofolio, Salemba Empat, Jakarta.

http://www.iyaa.com/finance/saham_ valas/2504168_3172.html.3, Oktober,2013.

https://www.infovesta.com/isd/articl e/article6.html.9,Oktober,201 $\underline{3}$.

http://www.bi.gi.id. Diunduh tanggal 14 Nopember 2013

http://www.yahoo.finance.com. Diunduh tanggal

Desember 2013

http://www.bi.go.id. Diunduh tanggal 11 Desember 2013

http://www.investor.co.id/home/pasa r-modal-indonesia-masihkuat-tahan sentimennegatif/61742. Diunduh tanggal 4 Februari 2014 